\title{
Educação do corpo e seus limites: possibilidades para a Educação Física na classe hospitalar*
}

Alexandre Fernandez Vaz ** Carmen Lúcia Nunes Vieira ${ }^{* * *}$ Michelle Carreirão Gonçalves ${ }^{* * *}$

Resumo: O presente trabalho apresenta alguns resultados de uma investigação que buscou alternativas social e pedagogicamente relevantes para o ensino de Educação Física em classe hospitalar. Acompanhados por instrumentos etnográficos, elaboramos experimentalmente alguns elementos para a consecução de uma proposta de Educação Física escolar naquele ambiente. Tratamos de questões como as alterações das relações de poder entre professores e alunos, a organização pedagógica das aulas, o significado da condição de estar doente. Consideramos, finalmente, as dificuldades da condição de professor nesse contexto e pontos que devem ser amadurecidos para a continuidade da Educação Física na classe hospitalar.

Palavras-chave: Ensino Fundamental, Educação Física, Educação Especial.

\section{O hospital e a educação do corpo}

A tradição ocidental propôs, em seus ditames pedagógicos, a necessidade da educação dos corpos. Esse movimento alcança características especiais na modernidade, quando se desenvolve um sem-número de estruturas e dispositivos que devem não apenas conter, mas disciplinar para potencializar o corpo e seus afetos no sentido de uma positividade produtiva.

* A investigação que dá origem ao presente texto compõe o projeto Convergindo olhares para alunos hospitalizados: conteúdos, metodologias e práticas, fi nanciado pela Fundação de Ciência e Tecnologia de Santa Catarina (FUNCITEC SC), com apoio do programa Pró-extensão/UFSC/2003. Resultados preliminares do presente trabalho foram apresentados no $12^{\circ}$ Encontro Nacional de Didática e Prática de Ensino, Curitiba, 2004.

** Doutor em Ciências Humanas e Sociais pela Universidade de Hannover, Alemanha; Professor do Programa de Pós-graduação em Educação do CED/UFSC; Pesnha; Professor do Programa de Pós-gração pucaça do CED/UFSC; Pesquisador do CNPq (Clências Humanas/Educação. Núcleo

*** Graduadas em Educação Física pela UFSC, mestrandas do PPGE/CED/UFSC. Núcleo de Estudos e Pesquisas Educação e Sociedade Contemporânea/CED/PPGE/UFSC

Movimento, Porto Alegre, v. 11, n. 1, p.71-87, janeiro/abril de 2005 
Uma das formas privilegiadas de educação do corpo é o conjunto de técnicas e práticas corporais pedagogizadas que conhecemos por Educação Física, cujas origens e desdobramentos, relativamente bem conhecidos, constituem área disciplinar que hoje se apresenta para todos os graus de ensino.

A educação do corpo, obviamente, não acontece apenas nos lugares e tempos da Educação Física, nem mesmo somente na escola e em outras instituições de atendimento pedagógico. As várias instituições totais ${ }^{1}$ de nossa sociedade - apenas para tomarmos um exemplo mais extremo - se sustentam por meio de dispositivos que incidem sobre o corpo, ou, dito de outra forma, o tomam como vetor privilegiado para a educação. É assim nas penitenciárias, nas escolas, nos hospitais e em todas as instituições que, estando inseridas em um contexto de espaço-tempo, vivem com certa independência, configuram-se como lugares que, de certa forma, circunscrevem uma dinâmica muito própria.

Nesse quadro, os hospitais aparecem como espaços exemplares nos quais o corpo comparece como protagonista. E neles que o corpo encontra, com larga extensão, seu desiderato nos tempos contemporâneos. No ambiente hospitalar ele muitas vezes se reduz a objeto operacional, manipulável, tratável e, paradoxalmente, tornado quase que a única dimensão que interessa do que resta do sujeito: sua funcionalidade.

De certa maneira, isso acontece na medida em que ocorre a transformação do indivíduo em paciente:

Uma vezinternado, opaciente sofre uma ruptura com seu cotidiano, desencadeadora deum sentimentode "falta de existência", comoseeleficasserepentinamenteem déficit para com o mundo: separa-se da família, da residência, do bairro, do trabalho, dos amigos e começa a experimentar um constante desfazer de suas certezas eidentidades; suas diferenças de sexo, idade e profissão tendem a ser anuladas em favor da condição de paciente; ele deixa de ter direitos sobre o próprio corpo e se vê separado, de modo abrupto, da vida que, dia a dia, construía e reconstruía sua identidade. Em diversas alas do hospital, a ausência de rostos, paisagens eobjetos familiares acentua a perda de referências eo sentimento de abandono. Nas UTIS, este aspecto ganha contornos mais graves. Nestes locais, os pacientes deitados em seusleitos parecem diminutos diante de toda a aparelhagem à qual seus corpos estão ligados. (SANT'ANNA, 2001, p. 31).

A condição de paciente, talvez necessária para o tipo de medicina que temos como hegemônica, coloca os indivíduos internados no patamar mais baixo de uma hierarquia que certamente começa com os médicos e passa por todos os especialistas em funções e segmentos corporais que estão abrigados no hospital. Não é à toa, portan-

1 Utilizamos aqui esta expressão, de Goffman (1974) com alguma liberdade.

Movimento, Porto Alegre, v. 11, n. 1, p.71-87, janeiro/abril de 2005 
to, que a forma de tratamento tenda a infantilizar os pacientes, nomeando, como lembra Sant'Anna (2001), com diminutivos as partes do corpo.

Dentre os dispositivos pedagógicos que compõem o ambiente hospitalar, encontramos um conjunto deles que, incidindo decisivamente sobre o corpo, encontra sua melhor expressão no cruzamento com vetores oriundos de outro ambiente institucional: a escola. Trata-se da classe hospitalar, espaço que pretende representar a continuidade da escolarização durante o período de internação de crianças e jovens. Ela procura dar mínima continuidade à rotina escolar e facilitar a reinserção quando da alta hospitalar.

A permanência dos alunos na classe hospitalar é bastante variável, assim como também os motivos pelos quais se encontram hospitalizados. Há aqueles com anos de internação e outros que lá estão apenas um dia; freqüentam a classe crianças e jovens internados para exames ou para uma intervenção cirúrgica relativamente simples, mas também pacientes oncológicos, anoréxicos e com outras graves enfermidades. Se a internação dura mais de dois dias, a escola de origem é contatada para que se acompanhe o estágio em que se encontra o aluno - isso não se realiza, como observamos, no que se refere às aulas de Educação Física -; quando da alta hospitalar o aluno leva consigo um relatório de atividades realizadas na classe.

Embora seja um ambiente dentro de outro, a classe hospitalar não pode ser entendida como um universo fechado, mas como resultante de várias condições, intra e extra-hospitalares, ou, dito de outra forma,

[...] na compreensão das interligações dos diversos aspectos [...] de sua realidade (a criança, a doença, os pais, os profissionais de saúde, oambiente hospitalar, oprofessor etc.) com aqueles sistemas domundo fora do hospital (contato com a escola deorigem da criança, adequações para a inserção da criança portadora de necessidades especiais na escola regular, encaminhamento de matrícula na escola regular quando da alta hospitalar para aquelas crianças que nunca freqüentaram escola antes, embora em idade de obrigatoriedade para tal). (FONSECA, 2003, p. 14).

Enquadrada como educação especial (BRASIL, 1994), mas transitando, no limite, com a escolarização regular, a classe hospitalar deve lidar, em princípio, com todas as áreas do conhecimento - no

2 Há casos de longa internação, mais de um semestre, que não representaram a necessidade de que os alunos repetissem a série porque, tendo freqüentado a
classe hospitalar, realizaram as avaliações quando da volta à escola de origem e foram aprovados.

Movimento, Porto Alegre, v. 11, n. 1, p.71-87, janeiro/abril de 2005 
que se refere à de quinta a oitava série ou às séries iniciais do ensino fundamental - ou com as atividades referentes à educação de zero a seis anos. Enquanto o hospital como um todo é lugar de controle bastante intensivo da corporalidade, dadas as condições de um corpo doente - tempos regulados, medicações, dietas, infusões, etc. - a classe oferece condições para um outro tipo de regulamentação corporal que inclui, entre outros dispositivos, as aulas de Educação Física.

\section{Possibilidades de ensino de Educação Física numa classe hospitalar}

A presença de aulas de Educação Física no contexto de uma classe hospitalar foi pensada por meio de uma investigação associada ao estágio supervisionado (Prática de Ensino de Educação Física Escolar) ${ }^{3}$ do curso de Licenciatura em Educação Física da UFSC. A pergunta que colocávamos dizia respeito à busca de alternativas socialmente relevantes para a prática pedagógica da Educação Física em um ambiente hospitalar.

Procuramos elaborar por meio de intervenções pedagógicas sistemáticas durante o segundo semestre de 2003, em um hospital infantil de referência de Florianópolis, SC, alguns elementos experimentais para a consecução de uma proposta de Educação Física escolar naquele ambiente considerando duas questões objetivadas: 1) a identificação de temáticas que pudessem ser trabalhadas no contexto da classe hospitalar e seus possíveis arranjos, observando que as experiências corporais não se esgotam naquilo que tradicionalmente chamamos de "prática"; 2) possibilidades de estruturar a organização e a temporalidade das temáticas, considerando que o tempo pedagógico deve ser determinado não a priori, mas pela própria dinâmica de trabalho.

Tínhamos clara a necessidade de observar os elementos que compuséssem, com especificidade, as relações pedagógicas presentes na classe hospitalar. Ficou para um outro momento uma preocupação que permanece central: a compreensão da extensão das pedagogias do corpo - dispositivos disciplinares e de controle, interditos e sujeições - em um ambiente hospitalar como um todo.

As aulas foram programas considerando a rotina da própria classe em que pesquisamos, que dispõe professores unidocentes

3 O trabalho está articulado com várias licenciaturas. Para maiores informações, consultar CARDOSO e col. (2004).

Movimento, Porto Alegre, v. 11, n. 1, p.71-87, janeiro/abril de 2005 
fixos, recebendo, para o ensino de quinta a oitava série, estagiários de diversas áreas que assumem o ensino da respectiva especialidade. O funcionamento das aulas nos dois grupos que investigamos - com mais ênfase o de quinta a oitava série, mas com incursões na educação de zero a seis anos ${ }^{-4}$ pode ser sumariamente assim descrito: no que se refere ao primeiro, sempre vespertino, a professora, quando chega no hospital, confere na lista de internos aqueles que podem vir até a sala de aula e vai às unidades para fazer o convite para que venham à classe, o que deve ser autorizado pela equipe ambulatorial responsável; no caso das crianças de quatro a seis anos, a dinâmica é semelhante, mas no turno da manhã e sempre com menor número de componentes.

A presença das crianças e jovens na classe hospitalar é algo rarefeita. As áreas de conhecimento geralmente ocupam, no caso do ensino fundamental, metade do período, antes ou logo após o lanche, servido por volta das $15 \mathrm{~h}$. Todo o processo se desenrola geralmente entre 13 e 17h. Para os dois grupos existe também o atendimento no leito, que significa trabalho pedagógico individualizado para crianças que não podem deslocar-se dos quartos ou apartamentos. No caso das de zero a seis anos, é permitida a presença de acompanhantes na classe hospitalar.

Nesse quadro emergia a dificuldade em delimitar quais seriam as possibilidades de trabalho em um ambiente no qual prevalecia a dificuldade ou mesmo impossibilidade de realizar práticas corporais, onde encontraríamos várias crianças e jovens que já em suas instituições de origem eram dispensados das aulas de Educação Física.

Como então se pensar em aulas de Educação Física em uma classe hospitalar?

\section{Classe hospitalar e Educação Física: articulações possíveis}

Entre os efeitos da "crise de legitimidade da Educação Física" (BRACHT, 1992) - datada pela literatura da área no início dos anos

4 A classe conta ainda, como apontado acima, com uma turma de séries iniciais do ensino fundamental e outra de estimulação que atende crianças em idade de berçário.

5 As aulas de Educação Física na escola são tradicionalmente lugares e tempos de contenção dos corpos, além de serem geralmente vedadas aos "sem saúde" contença dos corpos, alem de serem geralmentevedadas aos "sem saúde" ma vez que se diz, comumente, que as atividades físicas são benéficas à saúde.

Movimento, Porto Alegre, v. 11, n. 1, p.71-87, janeiro/abril de 2005 
1980, mas, possivelmente com focos mais antigos, como podemos ver a partir de Taborda de Oliveira (2001) e mais que presente ainda hoje - encontramos uma dificuldade ainda grande em consolidar a disciplina no contexto da formação escolar. Isso se expressa em várias questões que desafiam os professores quando tratam sua própria prática pedagógica como um problema a ser pensado ou, mais especificamente, quando procuram refletir contra ela e suas expectativas tomadas como óbvias: afinal, por que as crianças e jovens devem fazer Educação Física? O que deve ser ensinado nas aulas? Que conhecimentos são ali veiculados? O processo de conhecimento se operacionaliza diferentemente na Educação Física, se comparado a outras disciplinas escolares?

Em nossa pesquisa consideramos, desde o início, a ampla possibilidade de conhecer as experiências corporais ${ }^{6}$ como necessárias para que se apreenda uma dimensão fundamental das relações sociais, que se faz presente por meio do corpo e suas expressões. Consideramos, assim, que os temas na Educação Física podem ser duplamente experienciados: haveria uma dimensão mais ligada à mediação cognitiva, um conhecimento sobre os elementos da cultura que se comunicam pelo corpo e suas expressões os mais óbvios, mas não os únicos, talvez nem mesmo os principais, seriam os esportes, as danças, os jogos, a expressão corporal, entre outros; e teríamos também uma outra dimensão, de ordem também simbólica, que se estruturaria mais mimeticamente - um conhecimento somático, para além ou aquém do conceito, mas não irracional (VAZ, 2002).

Considerando o acima exposto, a investigação desenvolveuse com instrumental etnográfico, a partir mesmo das aulas de Educação Física ministradas e daquilo que envolvia seu entorno: os rituais de entrada e saída da classe, as formas de recrutamento dos alunos e alunas, além de outros elementos da cultura hospitalar que delimita de maneira bastante específica tanto o corpo e suas expressões quanto as práticas pedagógicas em geral no ambiente estudado.

6 Consideramos experiência corporal um conceito próximo daquele chamado por Taborda de Oliveira (2002) de corporalidade. Não desprezamos, no entanto, o que um Coletivo de Autores (1992) nomeou como cultura corporal, mas entendemos que os conhecimentos a serem tratados na escola e em instituições de atendimento a crianças de zero a seis anos devem privilegiar não apenas o que está sistemato a crianças de zero a seis anos devem privilegiar não apenas o que está sistematizado socialmente na forma dos esportes, jogos, acrobacias, lutas, entre outros, mas um conjunto mais amplo de experiências que se expressam, essencialm
por sua dimensão somática, organizadas ou não, singulares ou coletivas.

Movimento, Porto Alegre, v. 11, n. 1, p.71-87, janeiro/abril de 2005 
Nas próximas páginas apresentamos alguns resultados dessa investigação agrupados em torno de quatro categorias: as alterações das relações de poder entre professores e alunos, a organização pedagógica das aulas, o significado da condição de estar doente e, por fim, dois fragmentos das atividades desenvolvidas. Esperamos que, por meio dessas categorias narrativas possamos expressar, minimamente, algumas condições de possibilidade para a realização de aulas de Educação Física no contexto de uma classe hospitalar.

\section{Poderes e polaridades}

Uma das questões centrais que se colocaram para a prática pedagógica da Educação Física, mas também para outras disciplinas do conhecimento, na classe hospitalar diz respeito à inversão da polaridade nas relações de poder: os alunos eram convidados a participar das aulas, mas não obrigados a isso. Diferentemente do que acontece na rotina escolar, a da classe hospitalar coloca em jogo uma certa onipotência de professores ou estagiários, uma vez que as crianças e jovens podem não participar das aulas, levando a não haver, como foi o caso algumas vezes, um quorum desejado para as atividades.

Além disso, os alunos podem ausentar-se das aulas a qualquer momento, fazendo isso freqüentemente por motivação clínica para serem medicados, por exemplo - ou por vontade própria. Do ponto de vista da formação e mesmo do etos de ser professor, tratase de um duro golpe na auto-estima, como pode ser lido no extrato de um dos cadernos de campo:

Desde que comecei no estágio foi a primeira vez que não teve alunos. Toda a paciência que disse que devemos ter na outra aula [relato anterior] nesta ficou mais evidente. Um problema que não estava presente na aula passada éo maior peso no "fracasso" desta aula, a falta de alunos. Realmente precisamos ter muita paciência se quisermos continuar com este projeto das aulas, de Educação Física em especial, na classe hospitalar. Pois são problemas vindos de todos os lados. Para citar alguns evidentes: a limitação das crianças (doentes), o espaço físico (ou o não espaço), a dificuldade dentro do hospital (postos de enfermagem, reconhecimento do nosso trabalho), as saídas das crianças (medicação, exames, visitas, desobrigação...), o dia do estágio sexta-feira (dia de alta e licença das crianças) e por fim o mais grave, ao meu ver, a falta de alunos. Pois se não tem alunos, não temos nem o que superar, já que não tem aula.

7 Os comentários entre colchetes são acréscimos posteriores aos trechos dos diários de campo.

Movimento, Porto Alegre, v. 11, n. 1, p.71-87, janeiro/abril de 2005 
Talvez aí se coloque com maior visibilidade o que Adorno chamou de um tabu sobre a prática docente escolar. Diz ele dos professores e seu poder:

[... ] a opinião pública não leva a sério o poder dos professores, por ser um poder sobre sujeitos civis não totalmente plenos, as crianças. Opoder do professoréexecrado porque só parodia o poder verdadeiro, que é admirado. Expressões como "tirano de escola"lembram que o tipo de professor que querem marcaré tãoirracionalmente despótico como sópoderia sê-lo a caricatura do despotismo, na medida em quenão consegue exercer mais poder do que reter por uma tarde as suas vítimas, algumas pobres crianças quaisquer. (ADORNO, 1995, p. 103-104).

A minha hipótese é que a imagem de "responsável por castigos" determina a imagem do professor muito além das práticas dos castigos físicos escolares. Se eu tivesse que orientar pesquisas empíricas a respeito do conjunto complexo do professor, então estar seria a primeira a me interessar. Ainda que em ermos bastante brandos, repete-se na imagem do professor algo da imagem tão efetivamente carregada do carrasco. (ADORNO, 1995, p. 107).

\section{Organização das aulas}

Nossas anotações acima relatadas evidenciam um outro elemento importante para a organização das aulas de Educação Física na classe hospitalar que é a necessidade de um planejamento diferenciado, considerando vários aspectos que surpreendem aos que não conhecem previamente o campo: as manhãs de segunda-feira e as tardes de sexta-feira foram momentos ruins para a realização das aulas porque nelas acontecem, com mais freqüência, a chegada e a alta hospitalar; há grande variedade, não apenas numérica, mas etária, de origem geográfica e social entre os alunos e em cada dia de aula, o que dificulta a continuidade das atividades; as expectativas que os alunos têm a respeito da classe são muito diversas, muitas vezes oscilando entre uma retomada da rotina extrahospitalar e a quebra daquela então vivida e um momento de recreação instrumentalizado pelo uso do computador (a classe possui três conectados à www).

As temáticas trabalhadas em uma aula (com duração aproximada de hora e meia ou três horas - tarde toda -, conforme o dia) deveriam encontrar, portanto, um final nelas mesmas, mas ao mesmo tempo indicar uma possível continuidade para os encontros seguintes. A retomada constante e o registro de uma memória das aulas foi fundamental.

Isso tudo se alia a outros elementos da cultura hospitalar, como o caráter secundário que à prática pedagógica é destinado numa instituição clínico-médica; a posição inferior que os professores são colocados em relação aos que "cuidam" da saúde dos internos; a

Movimento, Porto Alegre, v. 11, n. 1, p.71-87, janeiro/abril de 2005 
situação de inferioridade do paciente, como citada antes, que o leva, paradoxalmente, a ver-se autorizado a atividades que comumente lhe são vedadas ou restritas na vida cotidiana - isso se expressa na recusa a ir para a classe e na preferência por ficar jogando um videogame no quarto ou na imposição da própria vontade nas atividades a serem feitas na classe (jogar no computador, por exemplo); a condição dos acompanhantes, geralmente adultos sem ocupação que em algum momento esteja desvinculada do cuidado das crianças e jovens.

No que toca à educação de quatro a seis anos, uma das dificuldades mais marcantes, que está intimamente relacionada à oscilação da presença das crianças na classe, diz respeito à construção de vínculos com os pequenos. Com a presença permitida da mãe - e a condição de menoridade imposta às crianças aliada à situação de hospitalizadas - torna-se difícil o estabelecimento de uma vinculação que permita adquirir a necessária confiança para o desenvolvimento das atividades.

\section{O significado de estar doente}

Uma questão bastante complexa e que se coloca como desafio para a classe hospitalar está relacionada à doença como algo que "deve" estar ausente das relações pedagógicas. Os professores da classe afirmam que ali as crianças e jovens devem exercer e ter reforçada sua identidade de alunos e não de doentes, tão presente nos outros espaços e tempos da rotina hospitalar.

Dessa forma não se motiva que a doença seja discutida em sala, que se torne assunto abordado. Isso para que não se reafirme, mais uma vez, a condição de paciente também no espaço pedagógico da classe hospitalar. Ali, diz-se, deve estar posta a condição de aluno.

De fato, as identidades de aluno e paciente, muitas vezes intercambiáveis, constituem dispositivos que determinam os contornos para o que se espera das crianças e jovens que freqüentam a classe. A condição de doente, no entanto, permanece nos momentos da classe hospitalar, por mais que seja escamoteada pelos professores. Isso se torna muito claro nas marcas corporais dos alunos, à vista de todos, como a temporária falta de cabelo dos pacientes oncológicos ou a presença de crianças e jovens conectados a equipamentos exteriores, como soros e sondas, ou ainda em posições em princípio inusitadas, como deitados em uma maca.

Talvez a enfermidade pudesse mesmo compor os temas a serem trabalhados na classe hospitalar, tanto porque é impossível

Movimento, Porto Alegre, v. 11, n. 1, p.71-87, janeiro/abril de 2005 
negá-la, quanto pelo fato de que compõe decisivamente a experiência corporal de cada um ali presente. Trazer ao plano da consciência a própria condição pode ser um passo decisivo, também no campo pedagógico, para a superação da situação em que se encontram aquelas crianças e jovens. Diz Susan Sontag (2002, p. 7-8) em sua auto-reflexão sobre a doença: "Meu ponto de vista é de que a doença não é uma metáfora e que a maneira mais honesta de encará-la - e a mais saudável de ficar doente é aquela que esteja mais depurada de pensamentos metafóricos, que seja mais resistente a tais pensamentos."

Vale lembrar uma bela passagem da obra de Walter Benjamin, segundo o qual o fluxo da narrativa, em mais um tributo freudiano de sua obra, desobstrui as possibilidades de cura:

A criança está doente. A mãe a leva para a cama e se senta ao lado. E então começa a lhe contar histórias. Como se deve entender isso? [...] Também já se sabe começa a lhe contar historias. Como se deve entender isso? [... Também jâ se sabe
como o relato que o paciente faz ao médico no início do tratamento pode se tornar o começo de um processo curativo. Daí vem pergunta se a narração não formaria o clima propício e condição mais favorável de muitas curas, e mesmo se não seriam todas as doenças curáveis se apenas se deixassem flutuar para longe-até a foz - na correnteza da narração. Se imaginamos que a dor é uma barragem que se opõe à correnteza da narrativa, então vemos claramente que é rompida onde sua inclinação se torna acentuada o bastante para largar tudo o que encontra em seu caminho ao mar ditoso do esquecimento. E o carinho que delineia um leito para essa corrente. (BENJAMIN, 1987, p. 269).

\section{Dois exemplos temáticos}

\section{Oprimeirodeles: expressãomimética}

Um dos conjuntos temáticos que podem ganhar mais espaço nas aulas de Educação Física diz respeito às atividades miméticas, aquelas que, como ensina Walter Benjamin (1993), se referem à capacidade de reconhecer e produzir semelhanças. Expressam essa capacidade humana as brincadeiras infantis, as dramatizações teatrais, algumas práticas esportivas - experiências que proporcionam momentos de reconhecimento de si e do mundo circundante. As brincadeiras, por exemplo, constituem

[...] expressões miméticas privilegiadas na infância, momentos organizados nos quais o mundo, tal qual as crianças o compreendem, é re-elaborado, contestado, dramatizado, experienciado. Nelas as crianças podem viver, com menos riscose interpretando de múltiplas formas, as situações que lhes envolvem o cotidiano. Desempenham umpapelelogo depois outro, seguindo, mas também reconfigurando, regras. São momentos de representação e apresentação, de apropriação do mundo. (VAZ; PETERS; LOSSO, 2002, p. 72).

Movimento, Porto Alegre, v. 11, n. 1, p.71-87, janeiro/abril de 2005 
Considerando o acima exposto, elaboramos uma temática que deveria ser desenvolvida na turma de quinta a oitava série por meio de expressões corporais na forma de uma dramatização. Citamos alguns fragmentos de um dos cadernos de campo:

\title{
$I^{a}$ aula
}

[...] Depois da conversa [inicial] apresentei a proposta da aula. Comecei com um alongamento para relaxar e depois com as expressões corporais. Primeiramente cada uma (Eu, Daniela ${ }^{8}$ [professora da classe] e Karina [uma aluna]) tinha que fazer uma careta, depois expressar sentimentos (dor, tristeza, alegria, paquera... ), enfim ia elencando alguns itens, elas também podiam dizero que seria a próxima expressão. A regra era que tudo deveria ser feito sem falar. Também propus que, em círculo, uma faria uma expressão e a outra teria que reagir a ela. [...] [como estávamos em poucas pessoas] Daniela sugeriu que poderíamos montar/escrever a peça hoje e representá-la na sexta-feira. Mesmo se não tivesse alunos suficientes, poderíamos juntar as classes $\left(5^{a}\right.$ à $8^{a}$ e $I^{a}$ à $\left.4^{a}\right)$. [...]

O tema inicial proposto pela aluna foi drogas e não o levamos adiante. Era, na verdade, um tema fortemente vinculado ao cotidiano da aluna, mas, pega de surpresa, a professora da classe preferiu escamotear a questão sugerindo que tratássemos de amizade. Sem condições de lidar com essa questão, limitamo-nos a concordar com a professora, o que mostrou, mais uma vez, as dificuldades que temos no enfretamento de questões-limite - o que se aguça sobremaneira em um ambiente no qual as situações limítrofes se colocam com muita radicalidade, como é o caso da classe hospitalar. De qualquer forma, a aluna, com nossa ajuda e da professora, montou um enredo bastante complexo, com muitos personagens e diálogos que procuravam representar as condições de seu cotidiano.

\begin{abstract}
Aula seguinte
[A bolsista] Volta [da ronda] com cinco crianças, de $1^{a}$ a $4^{a}$ série, não havia nenhum aluno de $5^{a}$ a $8^{a}$ série. Daniela, a aluna da aula anterior, teve alta. Começamos com uma conversa inicial e fizemos as apresentações. [...] [As crianças] Falaram que estava legal, mas que poderia ser diferente. Então a peça passou por uma super transformação. [Iniciamos, então, a aula de forma semelhando à anterior.] [...] Num segundo momento começamos a "ensaiar" a peça. Conforme [um de nós] lia o que havia sido escrito na aula anterior as crianças iam mudando erepresentavam. Estavam bastante participativas e criativas. A peça nãoera mais só sobre amizade e sim sobre um grupo de amigos e amigas que se encontravam e começavam a "gostar" uns dos outros, a namorar e por fim casavam.

[...] Representamos a peça duas vezes. A primeira foi antes do lanche e as crianças disseram que era só ensaio [...] Da segunda vez a peça saiu rápida, as crianças se vestiam erepresentavam com facilidade, parece que oensaio funcionoumesmo. [...]
\end{abstract}

8 Todos os nomes citados são fictícios

Movimento, Porto Alegre, v. 11, n. 1, p.71-87, janeiro/abril de 2005 
Algo bastante interessante pôde ser visto na atuação de dois alunos. Um deles falava constantemente dos problemas que lhe acometiam em uma das pernas (ficção e realidade aí se misturavam). O outro, representando o lugar social do médico, dizia-lhe, na pele do "Dr. César": "que nada cara, eu sou médico e não vai precisar cortar".

\section{Osegundoexemplotemático:esporte}

Em uma das aulas para a turma de quinta à oitava série, propusemos o tema esporte e dentro dele escolheu-se o voleibol, modalidade de forte apelo, geralmente ensinada nas aulas de Educação Física e produto de entretenimento bastante consumido via meios de comunicação. Discutiu-se com os alunos diversos aspectos do fenômeno a partir do levantamento que realizaram na internet. Nosso objetivo era fazer conhecer esse esporte em várias de suas dimensões, bem como constituir com os alunos uma forma, ao final, de praticar um jogo oriundo da modalidade.

Acompanhe-se por meio dos relatos em um de nossos cadernos de campo:

Discutimos item a item, passamos rapidamente algumas regras (equipes, bola, rede, $n^{\circ}$ de jogadores, pontuação... ), fundamentos (manchete, bloqueio, cortada, saque, toque, jogadas especiais) e o histórico e chegamos na discussão do voleibol comolazer e como trabalho, quando então dispusemos de mais tempo.

Procurando colocar outras dimensões do esporte e suas possíveis práticas e representações, apresentamos a possibilidade de observá-lo como trabalho, conformando a dimensão de espetáculo, tão conhecida pelos brasileiros. Além disso, apresentava-se também o selecionamento presente no esporte de alto rendimento.

Quando questiono sobre o voleibol como trabalho, Márcia logo fala "émuito puxado, tem que treinarmuito". Então aparecem algumas questôes: "nem todos podem fazer", "precisa ser bom mesmo". Falamos sobre a questão da exclusão (altura do jogador, orendimentomáximo). Márcia traz mais contribuições "mesmo queesteja machucado tem que jogar, porque senão perde seu lugar no time".

Apresentamos, então, duas outras possibilidades de prática e representação do voleibol, procurando entendê-lo em dimensão alternativa ao esporte de rendimento e sua centralidade, observando-o nas práticas escolares e nos momentos de não-trabalho.

Passamos a compará-lo quando praticado como lazer, é a vez de Batista dar sua opinião "ah como lazer não tem regras", pergunto se todos concordam com a opinião de Batista, logo Márcia e Ricardo retrucam "claro que tem", Márcia completa falando "em tudo tem regras, até numa brincadeira de esconde-esconde

Movimento, Porto Alegre, v. 11, n. 1, p.71-87, janeiro/abril de 2005 
tem regras", ao que Ricardo complementa "lógico senão não tem brincadeira". Batista, depois de tantas opiniões contrárias, se explica dizendo "concordo que tem regras, mas são mais flexíveis". Comentamos sobre as diferenças do esporte (lazer/brincadeira $x$ trabalho/rendimento) e comparamos o esporte nesses dois diferentes aspectos por meio de duas fotos que Batista e Joice haviam selecionado na Internet. Uma das fotos mostrava homens e mulheres jogando na praia informalmente sem uniforme (lazer/brincadeira) e na outra um jogo de voleibol, com as equipes uniformizadas, árbitros, público, todo os componentes do esporte oficial (trabalho/rendimento). A discussãoémuito produtiva, todos contribuem, apenas Jerusa fala pouco e quando questionada diz somente "nunca joguei vôlei, sou muito baixinha". (Tem problemas na coluna vertebral).

Além das diferenças comentamos também oaspecto doesportena versãoespetáculo/ show. Então passamos para o esporte na escola. Márcia, logo diz "na escola écomo lazer", aproveitando a discussão anterior. Questiono se não tem outros objetivos, logo Márcia se prontifica: "para aprender os esportes e depois escolher o que mais gosta". Exponho sobre o esporte ser um fenômeno produzido pela sociedade (que faz
parte da cultura corporal), cabendo à escola, por intermédio da Educação Física, a socialização compreensão desse fenômeno. Falo da apropriação do conhecimento sobre o esporte dominante e da possibilidade de significá-lo de outra forma e transformá-lo no esporte "da" escola, já que, como eles mesmos reconheceram, o esporte derendimentoéaltamenteexcludente.

Depois de toda a discussão passamos para um segundo momento. Proponho o desafio de construirmos/elaborarmos um jogo (de vôlei) que todos da classe dentro de um hospital (não só os que estavam na classe, mas também alunos futuros) pudessem jogar e/ou participar. Ficamos um bom tempo elaborando as regras e estrutura do jogo, os alunos pareciam entusiasmados.

\section{Ojogo: Voleistal}

$l \rightarrow$ Coma rede baixa + ou $-1,60 m$ (já que havia pessoas baixinhas, de cadeiras de rodas, ou atémesmo em macas todas poderíamjogarnesta altura); $2 \rightarrow$ Nomínimo uma dupla (duas pessoas, uma de cada lado); $3 \rightarrow$ Quadra + ou - 4 × 3 m (para não cansar); $4 \rightarrow$ Bola leve (para não machucar); $5 \rightarrow 15$ pontos (também para não cansar muito e ser mais rápido); $6 \rightarrow 3$ sets; $7 \rightarrow$ Sem cortada, sem bloqueio (comoaredeébaixa ealgumas pessoas podem estar "machucadas", não tem sentido ter estas jogadas); $8 \rightarrow$ Pode segurar e pode jogar com 1 ou com as 2 mãos (para facilitar, pensando que alguém pode estar com soro, ou impossibilitado de usar as duas mãos, mas também podendousar): $9 \rightarrow$ Quatro passes; $10 \rightarrow$ Saque-jogara bola com uma mão e também pode dar uma "cortada fraca" (que seriajogara bola para o alto com uma das mãos e bater com a outra mão, desde que não muito forte); $11 \rightarrow$ Sem libero (poucas pessoas, não tem sentido ter líbero); $12 \rightarrow$ Nãopodeinvadir a quadra enem encostarna rede.

Acabamos a elaboração do jogo e fomos fazer o lanche. Depois da construção do Voleistal a proposta éjogar. Mas como está chovendo e o pátio (área de sol) não pode ser utilizado esta parte (...) fica comprometida. Tentamos "arrumar" a sala

9 Toda a construção/elaboração do jogo foi em conjunto (crianças x professor) e as observações entre parêntese de cada regra são considerações das crianças e nossas também. O nome do jogo foi sugestão das crianças.

Movimento, Porto Alegre, v. 11, n. 1, p.71-87, janeiro/abril de 2005 
parajogarmos, porém eram muitos os problemas. Tinha os computadores, o espaço da sala é pequeno, e para piorar a mesa que faria o papel da rede (conforme sugestão de Bruno) não cabe atravessada na sala. Concordamos que estava difícil jogar hoje devido a tantos problemas. Além do que, Melina tem que sair, pois chegou visita para ela e seu pai veio chamá-la. Brunoé relutante quanto a nãojogar e diz "então vamos jogar amanhã", ao que explico que é sábado e não tem aula, ele não se convence e diz "o que éque tem, vamos professora, não temos nada para fazer mesmo!". Com a saída de Melina, Bruno parece se conformar.

Então desistimos (por hoje) de fazer o jogo e transferimos a proposta para a próxima sexta-feira (dia do estágio). Mudamos a proposta e cada um poderia escolher o que fazer.

$\mathrm{Na}$ aula seguinte tivemos dificuldades em reunir alunos para a execução do jogo, o que não apenas impediu que a atividade encontrasse sua finalidade, mas nos deixou grande frustração.

\section{Considerações finais}

A Educação Física encontra seu lugar na classe hospitalar na medida em que estende o trato temático na direção de uma compreensão da presença do corpo e suas expressões na cultura contemporânea. Nesse sentido - e novamente não é caso apenas da classe, mas da escolarização em geral - é preciso pautar os limites corporais como uma questão a ser incorporada de forma direta no trabalho pedagógico.

Uma questão a ser destacada - e, novamente, não apenas para a classe hospitalar - é a necessidade de valorizar os conhecimentos e experiências que os alunos trazem consigo com vistas a sua possível reelaboração. Esse é um ponto muitas vezes anunciado, mas nem sempre levado a sério. Ele envolve, no fundo, as intrincadas relações entre o que comumente chamamos cultura popular e cultura elaborada, sendo elas costuradas pela forte presença da indústria cultural. Muitas vezes as crianças e jovens têm como referência imediata o que vivenciam pela mediação dos esquemas da indústria cultural, notadamente aquela que reforça os ritmos acelerados de sons e imagens que se sucedem sem parar. Não é à-toa que uma das "atrações" da classe hospitalar é um computador. Não se trata, obviamente, de simplesmente propor a exclusão da informática ou de outros artefatos tecnológicos, mas de conferir-lhes a devida importância como meios e não como portadores de finalidades.

Pensando um pouco na formação (inicial e continuada) e no etos do professor, é bom lembrar as dificuldades subjetivas com a condição do corpo doente, com a dor dos pacientes:

Movimento, Porto Alegre, v. 11, n. 1, p.71-87, janeiro/abril de 2005 
O que me mais me marcou neste evento [Dia das Crianças] foi a passagem que fiz na oncologia infantil, para fazer pinturinha nas crianças que faziam quimioterapia. Realmente tive que me controlar, "coloquei uma certa máscara", me fiz de "durona" para suportar tanto sofrimento, conversei com as crianças enquanto desenhava seus rostinhos abatidos, seus bracinhos magros. Lembro, claramente, de dois em especial: Michel e Bárbara. Michel, de 6 anos, me pediu um boneco no braço, quando perguntei se estava doendo, quando fez uma careta enquanto pintava seu bracinho magérrimo, ele me respondeu "já estou acostumado"; sorriu quando viu o pica-pau desenhado em seu braço.

Esse ponto ganha maior densidade se considerarmos que facilmente podemos escorregar para uma perspectiva assistencialista e culposa em lugar da necessária e responsável solidariedade pedagógica. Isso não nos escapou, apesar de todas as contradições experienciadas:

Todo o evento foi especial e difícil, principalmente a visita à oncologia, mas proporcionar e ver um pouco de alegria nas carinhas de Bárbara e Michel foi mágico, recompensador; receber dois lindos sorrisos de crianças em tal estado, numa mesma tarde, foi maravilhoso. Acho que não é só esse o papel de um professor, mas um pouco de humanidade nesta hora não faz mal a ninguém.

Por fim, quatro questões, entre outras, ainda permanecem orientando: 1) a necessidade de trabalhar com mais densidade as memórias dos alunos internados no que se refere às práticas corporais - o que já fizeram, o que conhecem, o que não podem fazer e assim por diante; 2) tudo aquilo que envolve a organização pedagógica das atividades no que toca ao tempo pedagogicamente necessário para as atividades; 3 ) o desenvolvimento de material didático de apoio tanto para os (as) alunos (as) quanto para os (as) professores (as) e estagiários (as); 4) a importância de estudar a Educação Física no contexto da classe sem desvinculá-la de outras disciplinas do conhecimento - rompendo, sempre que possível, as barreiras entre elas - e das formas de governo do corpo, para além da classe, presentes no ambiente hospitalar.

Movimento, Porto Alegre, v. 11, n. 1, p.71-87, janeiro/abril de 2005 
Education of Body and its limits: possibilities of Physical Education at hospital classroom

Abstract: This paper shows some results of a research which aim was to find social and pedagogic relevant alternatives of Physical Education teaching in a hospital classroom. It was proposed some points toward a proposition of Physical Education teaching, which was accompanied by ethnographic instruments. Changing of teacherstudents power relations, of organizing classes and of meaning of being sick were important research points. Finally, it was observed the difficulties of teacher in this context and what should be improved to continuing of Physical Education in the hospital classroom.

Keywords: Elementary School, Intermediate School, Physical Education, Special Education.

Educación del Cuerpo y sus límites: posibilidades
de la Educación Física en la clase hospitalaria
Resumen: El trabajo presenta algunos resultados de una
investigación que procuró alternativas social y pedagógi-
camente relevantes para el enseño de Educación Física
en clase hospitalaria. Elaboramos experimentalmente
algunos elementos para la consecución de una propuesta
de Educación Física escolar en tal ambiente. Esto fue acom-
pañado por instrumental etnográfico. Tratamos de cuestio-
nes como las alteraciones en las relaciones de poder entre
profesores y alumnos, la organización pedagógica de las
clases, el significado de estar enfermo. Consideramos, al
final, las dificultades de la condición de profesor en esto
contexto e algunos puntos que deben ser desarrollados
para la continuidad de la Educación Física en la clase
hospitalaria.
Palabras-clave: Escuela Fundamental, Educación Físi-
ca, Educación Especial.

\section{Referências}

ADORNO, T. W. Educação e emancipação. Petrópolis: Vozes, 1995. 190 p.

BENJAMIN, W. Obras escolhidas II. São Paulo: Brasiliense, 1987. 277 p.

Obras escolhidas I. 6a ed. São Paulo: Brasiliense, 1993. 253 p.

BRACHT, V. Educação Física e aprendizagem social. Porto Alegre: Magister, 1992.

Movimento, Porto Alegre, v. 11, n. 1, p.71-87, janeiro/abril de 2005 
BRASIL, Secretaria de Educação Especial. Política Nacional de Educação Especial. Brasília, MEC/SEESP, 1994.

CARDOSO, T. M. e col. O estágio supervisionado articulando ensino, pesquisa e extensão em uma classe hospitalar de $5^{\mathrm{a}}$ a $8^{\mathrm{a}}$ série. In: Anais do $12^{\circ}$ Encontro Nacional de Didática e Prática de Ensino. Curitiba, PUCPR, 2004 [Cd-rom].

COLETIVO DE AUTORES. Metodologia do ensino de Educação Física. São Paulo: Cortez, 1992.

FONSECA, E. S. da. Atendimento escolar no ambiente hospitalar. São Paulo: Memon, 2003. 97 p.

GOFFMAN, E. Manicômios, Prisões e Conventos. São Paulo: Perspectiva, 1974

SANT'ANNA, D. B. de. Corpos de passagem: ensaios sobre a subjetividade contemporânea. São Paulo: Estação Liberdade, 2001. 127 p.

SONTAG, S. A doença como metáfora. 3ª ed. Rio de Janeiro: Graal, 2002.108 p.

TABORDA DE OLIVEIRA, M. A. Práticas pedagógicas da Educação Física nos tempos e espaços escolares: a corporalidade como termo ausente? In: BRACHT, V.; CRISORIO, R. A Educação Física no Brasil e na Argentina: identidades, desafios e perspectivas. Campinas: Autores Associados, 2003, p. 155-177.

VAZ, A. F. Ensino e formação de professores e professoras no campo das práticas corporais. In: VAZ, A. F.; SAYAO, D. T.; PINTO, F. M. (Org.). Educação do corpo e formação de professores: reflexões sobre a prática de ensino de Educação Física. Florianópolis: EDUFSC/INEP, 2002, p. 85-107.

VAZ, A.; PETERS, L. L.; LOSSO, C. D. Identidade cultural e infância em uma experiência curricular integrada a partir do resgate das brincadeiras açorianas. Revista da Educação Física/UEM. Maringá, vol. 13, n. 1, p. 71-77, $1^{\circ}$ sem 2002. 